\title{
Proposed Approach to Develop the Measurement Methods of Accounting Disclosure for Support of the Competitiveness of Business Organizations
}

\author{
Hebatallah M. Alkashef \\ Accounting Department, \\ Faculty of administrative and \\ finance, \\ Taif University,
}

\author{
Mohammed Abdelrahman \\ Alaydi, PhD \\ Professor of Accounting, \\ Faculty of commerce, \\ Port Said University,
}

\author{
Mohsen M. Alyamany, PhD \\ Assistant Professor, \\ Faculty of commerce, \\ Port Said University,
}

\begin{abstract}
Search seeks to identify the axes of the development of the instrument cluster accounting disclosure on the basis of the results reached from previous studies in this area, which define the trends of the targeted development methods of management accounting in the light of the expected changes in the environment of the activity of companies; from which can raise the ability of economic unity to achieve competitive advantages.
\end{abstract}

\section{General Terms}

Management Accounting- measurement methods - accounting disclosure

\section{Keywords}

Develop the measurement- disclosure- competitivenessmanagement accounting.

\section{INTRODUCTION}

In accordance of the results of the generated from previous studies, which dealt with the development of methods of management accounting, environmental variables in the Egyptian market as part of the global market, it can be argued that sufficient justification must be a framework for "the management of the pricing" in economic unity; at the top of those justifications the commitment of the Parties for the international trade organization of a progressive reduction in tariffs, which will lead to increased competition in the world markets, which required the officials in the business organizations in general, and in the states seeking progress in particular work in several directions:

1. The development of methods of production to raise the level of product quality and performance career development under the sale price is acceptable in the local market and international levels.

2. The development of management systems to ensure that the cost of achieving the profit margin of unacceptable by the owners and shareholders.

3. Seek the development of export markets and the search for new markets to benefit from economies of scale.

4. Taking into account the social pressures arising from the evolution of technology control on the environment.

5. The reformulation of the goal of the organization including variables and keep pace with the new global and local.

\section{BASIC TECHNIQUES}

All material on each page should fit within a rectangle of $18 \mathrm{x}$ This requires the need for a mechanism to determine the price of the product I, in the light of a strategy based on three elements:

1. the need to seek to improve the results of economic unity through the improvement of the results of the major operations, including raises their competitiveness in the global market.

2. the necessity of adopting the concept of the world product, any unacceptable in terms of specifications and quality levels in international markets.

3. Work to develop effective management of cost-hour session of the activity.

As long as the organization does not have the usually ability of long-term to achieve competitive advantages through cost reduction or the followers of any strategy another distinct, because any advantages to achieve in the short term will pay its competitors to move quickly to provide a new product at competitive prices, and to continue to support their product benefits, which would push the economic unit to take countermeasures, and thus the continuous competition [1] If it is inevitable that the pricing policy disappear take into account three key variables and cost, quality and functionality of the product, the situation prevailing competition in the domestic market and international levels, with the aim of the survival of economic unity of the continuation of its activity, through the provision of high quality product, privileged position in the job performance, and meet the expectations of the clients, taking into account the prices of competitive products and alternative views.

The success of the organization in identifying prices of their products not only on its efficiency in the management of the cost, and its attempt to stimulate the implementing partners to act strongly through the granting of authorization, and measurement systems effective incentives, as well as the availability of appropriate information on market conditions the domestic and international levels. It requires the pricing policy based on the existence of a comprehensive framework for a series of economic unity, builds on the [2]:

1. A clear definition of the roles of the five posts president represented in engineering design, production, marketing, accounting, management, economic studies.

2. Streamlining of the reciprocal relationships between the functions of the Chairperson including lead 
access speed information feedback to ensure improvement and continued development of performance, and the rapid response of the variables in the product market.

Although many researches and studies that paid attention to the above-mentioned but are partial handling of aspects of the problem, international cared for the rationalization and cost reduction [1][2][3][4] or the development of systems of accounting information[5][6][7], or on the quality of the product and the continuous improvement of initiated by Feigenbaum) and research and development of many of the book of them ( Juran , Lundvall , Plunkette \& Dale , Rayner) [8] . That is what pushed the researcher to propose pricing model on building a comprehensive framework that considers the different variables affecting to set the price of the product I guarantee him the competitive strength in the domestic market and international levels.

And will the competitive pressures, arising from the global trend toward the liberalization of international trade and the clustering of many major companies in trade unions with a view to achieving savings in support of market power through the integration of the value chain, to stimulate many facilities to adopt a new strategy that would enable them to survive in the market, we can call it "strategy to respond to the requirements of the international market." That strategy requires that the evolution of economic unity of its structures and systems, first and foremost the measurement systems accounting report, including can be applied with modern methods designed to reduce cost while maintaining the quality of the product, and the profit margin of patients can shareholders of the pricing of products at competitive prices and ensure their viability. The development of the instrument cluster Systems Accounting Report of one of the most important challenges facing the contemporary facilities, as the main product of financial information necessary to take decisions on all administrative levels in conditions of not to ascertain, the difficulty of the programming of the decisionmaking process; because of the slow pace of change in the market requirements and the level of art prevailing production, at the same time it seeks the facilities for continuing improvements in its output to ensure access to an appropriate share of the market for the product or service. It adds to the difficulty of the increasing competition from the continuous decline in the time available to the competitors for interaction with the market changes, given the consequent decline in the duration of the product in the market. This means the need to work to lift the ability of economic unity to respond to the rapid and sound development of the market variables, which requires tougher punishment need to provide relevant and accurate information and temporariness decision makers [9].

A strategy to respond to the requirements of the international market:

Requires the adoption of economic units strategy "to respond to the requirements of the international market," the need to develop systems of traditional manufacturing, transfer systems of flexible manufacturing, including can be changes in the specifications of the kinds of Product in accordance with the change in the wishes of the clients in the international market and competition; those systems the consequent increase of capital expenditures and high indirect costs because of the high processing costs and the costs of the design and the restructuring of productive centers, and the high costs of maintenance and the supervision and training of workers to upgrade their skills commensurate with those systems. As well as the emergence of other types of costs such as the costs of design and develop systems of computer programs [10] On the other side will decrease the costs of direct employment as a result of the reduced number of operators of machinery and reduced the time required for the preparation and operation. This change in the Mix will lead to the inadequacy of the traditional foundations for the allocation of indirect costs, which necessitates the need to search for new bases. As well as the benefits of the direct and indirect consequences of those systems be consecutive accumulative over the long term. In view of the importance of those benefits from the perspective of the value of the customers and shareholders, require the need to develop the measurement tools and the Report [11] This requires the need to know how and what the implications of the adoption of the "strategy to respond to the requirements of the international market" on measuring systems accounting report as an input to support its role in the success of the implementation of the Strategy

And requires the application of the "strategy to respond to the requirements of the international market" flexibility and productivity. Known as productive flexibility to the extent permitted by the Economic Unit for customers to influence in the specifications of the products or services performed by. This starts the extent the willingness and ability of economic unity of the change specifications to meet the requirements of the market, and ends the production output Customizing is in accordance with the combination of normative standards that is configured by the Economic Unit, referred to the wide response to customer [12] Mass customization. And to respond to the wishes of the clients in the manufacturing systems as a floppy connected, starts the first limit low levels when the client is unable to request a change in the basic specifications for the product or service, alone the continuing submission to high levels of response, through the design of a product or service to meet the full requirements of the market [13] (Pine \& Gilmore).

Building on the success of the strategy to respond to the requirements of the international market on three factors are manifold:

\section{First: adopting systems flexible manufacturing}

Verify that systems of flexible manufacturing many advantages and the consequent some problems [14] One of the most important advantages provided by the speed in response to changes in the product markets, because of the lifting of the Organization's ability to achieve efficiency and effectiveness of the performance, the continuous improvement in the quality of the product, and flexibility in the addition of new production lines, reducing waste and harmony, the optimal exploitation of devices and equipment, as provided in the areas required to complete operations, and reduce the cost of inventory, and the cost of the handling of the articles, and failover and industrialization, thus reducing the time of the overall performance of the Lead Time. Which lead to savings in the direct and indirect employment. The advantage of other important achieved the highest degree of efficiency in production processes, in view of the rapid cycle of feedback which provides the management of economic unity of the image of the full and immediate for the development of production and employment. Which reflected in lifting their ability to increase the volume of production at a reasonable cost. It was confirmed by data published, has decided to many of engineers in the installations applied these systems lower production time by $40 \%$, and $30 \%$ of productive employment and to take greater advantage of the available capacities by $12 \%$, which led to lower unit cost by $12 \%$ [15]' but it requires 
innovative operators to contribute to the achievement of real flexibility. It also requires an initial investments high represented in the initial cost of operating equipment and computers and programs, as well as the cost of incorporation, and planning, and the cost of changing the support systems and adaptation, and create a new kind of issues that organizations should seek to face them efficiently, the most important of which is the need to make appropriate changes in the systems of economic unity, organizational structure and measurement systems accounting report where must be developed for many reasons, including: [16]

A. the increasing need for new strands of different accounting information.

B. the magnitude of the financial investments necessary to implement those systems, while the benefits of the direct and indirect generated such as reducing production cost and inventory, and improve the quality of production and satisfy the wishes of the clients, and upgrading the capacity of the Organization competitiveness occur in succession accumulative over the long term. In view of the importance of these benefits from the perspective of shareholder value and customers, the accounting system to provide appropriate tools for their measurement, and provides appropriate reports and periodic reports to clarify what has been achieved during the period.

C. the focus has traditionally been on the financial reports and short-term, while systems require a flexible manufacturing the availability of information to clarify the strategic directions of the long-term. This requires the need to develop criteria for the measurement of the accounting report on performance and long-term strategic.

Secondly: the existence of associative relations between organizational units within the Organization.

Affected by the success of the strategy of "to respond to the requirements of the international market" on the efficiency and effectiveness of the relational relations between organizational units within the Organization, which take one of the three forms [17]:

A. the aggregate relations (combo) Pooled Interdependence there when complete organizational units of its tasks independently and interdependent at the same time.

B. consecutive relations Sequential Interdependence there when a serial sequence of intermediate units transferred between organizational units until the handover of the final product to the customer.

C. reciprocal relations Reciprocal Interdependence and represents the highest forms of associative relations as it moves the intermediate products forward and backward between organizational units several times until the handover of the final product to the customer.

So, there are three types of relations the indissoluble link between organizational units simultaneously. The efficiency and effectiveness of the relational relations and the extent of the abundance of information the temporary and convenience to help managers to take decisions in the light of the uncertainty of the economic activity in general, and in the recent period in particular. Which means the need to develop the various dimensions of measurement systems accounting report including can provide such information. Those dimensions in scale and scope, complementarity and integration and clustering Aggregation Temporal Timeliness [18].

The range is determined in the light of the accounting systems of conventional arms to work on providing financial information relevant historical focus of the pool, the so-called information the narrow scope of the Narrow Scope Information. On the other hand, information broad BoardScope Information is as well as information the narrow scope of, other information, with an external perspective future trends [19].

Integration is intended to provide information relating to the activities of the organizational units within the economic unit, as well as information on the impact of the decisions taken by any unit on the performance of other units. These relate to the information the inputs and outputs and the technology used. For example, reports information on the size and type of output generated by the various organizational units, and related information concerning the costs and revenues and prices [20].

Intended synthesis dimension to provide consolidated information on financial performance, such as reports summarized the activities of the sub-units or functional, whether in the form of periodic reports, or special reports resulting from support models administrative resolution such as inventory models, and the analysis of what if, analysis of profit, size and cost. Reports provide collected the necessary information to assist managers in the ongoing evaluation of the impact of their decisions on the quality of production and efficiency of the various organizational units of the SubCommission.

Tameness sub-dimensions are periodic reports, the rapid preparation and delivery. Periodic means providing information repeatedly and orderly, while speed mean the time that elapsed between the request and provide information to the user. Once the possible provision of information periodically (daily or weekly) the time difference between the request for information made available a few this was evidence of the efficiency and effectiveness of the accounting system from the angle of the time dimension.

It is clear from the foregoing that the four dimensions of the accounting system are interdependent and interrelated, where information can be provided extensive information and integrated synthesis of, or in detail. Similarly, the dimensions of the scope and integration and clustering could be linked to a large extent with after ephemeral. Which means that the recognition of the managers of a particular dimension may coincide with other dimensions. It must therefore be accurate when examining the impact of adopting a strategy to respond to the requirements of the international market" on each separately.

Thirdly: the development of measurement systems accounting report

The focus of the proposed entrance to develop the instrument cluster accounting disclosure on two pillars:

The first pillar: within an integral framework based on the re-arrangement of the methods developed in the management accounting

A follower of accounting techniques developed in the field of management accounting since the late 1980s of the twentieth century so far, noting that the researchers and professionals have exerted much effort in an attempt to create and develop methods to help quick response to changes in the environment 
of the activity that witnesses a fierce competition; require the Organization sought to improve the quality of the Product in accordance with the wishes of the clients, at the same time the obligation imposed by prices competition conditions prevailing conditions, with the need to preserve the integrity of the environment, which is placing additional cost-the established and requires the development of the Organization its goal to ensure the survival and continued in the market need to work to maximize value for customers and shareholders through the production of a product to meet the wishes of the clients, in the light of market prices, with the consent of the shareholders and the owners, which means the necessity of seeking to reduce cost and improve The quality and the preservation of the environment, and commitment at prices imposed by competition conditions prevailing.

It is here to shoulder the efforts of the Chief Administrative Officer, engineers and accountants to search for the means with which to achieve this objective, this effort started from the functional analysis, which was developed under the name of "architecture value", and an analysis of the processes and products, for operations, be an analysis of the major operations of the economic unity to the range of activities of each operation, and then select the value-adding activities and non-hosts the value and an analytical study to determine the mechanisms of support activities through the inventory and to identify the main factors affecting them and to their development and to try to learn how to minimize or exclude activities host-value in the light of the expected to occur in the case of exclusion, and required by this exclusion from the redrawing of the map of the flow of operations[21] ; as a result of the emergence of new methods of production in the appropriate time (JIT Just in time, the planning of the project resources Enterprise Resource Planning (ERP), which aims to reduce costs through the exclusion of activities of host-value, and reducing the time of achievement[22].

For product analysis begins to select the function or functions of the College of the product, which reflect the benefits for customers from behind to get it, and then to determine the components of the product, and the impact of each component of the total benefits accruing to the customer of the use of the product. In other words, the identification of the function of each component, following an assessment of the importance of this function as input to determine the degree of impact of each component on the overall performance of the product. Using the results of the previous analysis in the redesign of the components, both through the integration of some of the components and functions of the new component, or the redesign of the component to reduce production costs through a reduction in the time of production or use of alternative materials. On the basis of the results of the previous analysis of the design of the product as a whole in a way that guarantees its compatibility with the wishes of the clients, maintain quality but to seek improvement, with cost reduction.

This prompted the emergence of a new style of the Department of Economic Unity to reduce production time within the framework of maintaining quality, and maintains and supports the competitive advantages of economic unity, which was re-engineering [23] [24].

In response to the accountants for the above-mentioned, sought to develop accounting methods that are compatible with the requirements of the directions of the Chief Administrative Officer and engineers design and production, and contribute to the achievement of the objective 4D (improving quality - cost reduction - the preservation of the environment - a commitment to market prices). Among those methods cost method in accordance with Activity-Based activity costing (ABC), which is aimed at achieving accuracy in measuring costs through linking the cost elements consuming activities, and the units of the final product according to the hard drives the cost will be determined in the light of the extent of benefit product unit of this activity. This provides the information to help the Organization to streamline the costs. The interaction of this method with the results generated by the Value Engineering in achieving improvements of value to the cost of the product through the reduction of all of the time of achievement, and activities of host-value, as well as the reduction of the components of the product and improve its quality and consistent with the wishes of the current customers for economic unity, and then maintain them, and attract new clients [25].

Under the burden of the competitive pressures, in response to the engineering efforts in the area of product development in the light of market prices, accountants developed a new entrance to the cost called "target cost". And the idea of this entrance and the survival of economic unity of the continuation of its activity depends on its ability to produce relevant specifications appropriate quality, in the light of the prices imposed by market forces, in the light of the limited capacity of the Organization to move on. This is the entrance to determine the market prices through economic studies and marketing by established, then there shall be set off against the profit margin of patients, which guarantees the organization continued link stocks campaign external financiers, the difference represents the costs to the implementation of the various operations of the Organization in its borders, starting from the acquisition of factors of production and the end of the conduct of the final product and after-sale services. Which pay all officials of the Organization to reconsider their activities, and seeking to develop work in line with the cost-effectiveness of the imposed by market forces, by trying to take advantage of the technological development in the improved performance, and application of methods by which cost reduction, including the method of production in time Just In Time, which aims to minimize the Buffer Stock as inspection activities, receipt, storage, activities of host-value, can be replaced the procedures for examination and takeover of the supplier itself, with scheduling orders access consistent with production schedules to be formulated in the light of the customer requests, which means minimizing inventory contained the property and inventory of the full production, which inevitably lead to reduce costs.

As many facilities for the application of the same methods to achieve competitive advantages to enable them to survive, those facilities to the point where it is difficult to further cut costs, which charged the facilities of interrelated activities to try to improve their competitive advantages through strategies based on complementarity and cooperation rather than competition; hence the many techniques that are compatible with those strategies of comparison better Benchmarking which seeks enterprises of which benefit from the successful experiences of both at the level of the Organization itself (compared to the best internally) or on the level of the enterprises operating in the same field (compared to the best externally) with the aim of holding additional improvements in its activities contribute to the support of the chances of survival and their continuation in the market; in addition to the above sought relevant installations of integrated activities to form federations either Took the form of integration or union or participation in information, with a view to 
improving the value chain, and contributes to the achievement of a satisfactory value for each of the parties associated with the activity (shareholders and suppliers and customers and employees) or affected by the (represented in the various sectors of society)[26].

In the light of the above, it can be noted that all the previous methods, whether administrative or engineering accounting or designed to help the organization to survive in the market of the formation of a strong competition and rapid change resulting from the economic, social and political developments, the speed of technological change both in the area of manufacturing or marketing or in the field of management information systems and accounting; which necessitates the need to rearrange such methods within an integral framework based on a network of Relational relations, support the ability of these methods together to achieve the ultimate goal of the Organization, the researcher sees that take the proposed entrance Fig 1 .

In the light of this integrative entrance to the proposal to rearrange the drafting methods developed in the management accounting including lead to maximize the value of the application of those methods, the general steps to apply:

1. The study of the competitive position of the Organization in the market with a view to listing identifying competitive advantages, and the extent to which they could be developed under the changes expected in market competition conditions of current and projected, then estimating prices expected market for the products of the Organization.

2. The study of funding to the discretion of the factors affecting the orientations of the investors in the future, and therefore the profit margin of patients, which ensure the continuity of shareholders and investors in support of the activity of the Organization in the future.

3. The cost estimate for each target product by subtracting the profit margin of the patients from the market price of the expected acceptance of the product and that cost the limits to the completion of all activities in the framework of, from the design of the product and identify the necessary needs of factors of production and get it, through the production processes and other operational activities, and the marketing activities and the end of the service after the sale.

4. Compared with the cost of the former target appreciation for each product in the previous step actual cost of current, and here we will face one of the three possibilities:

a) The actual cost less than the target cost.

b) The actual cost of equal target cost.

c) the actual cost more than target cost.

5. In both cases ( $a, b)$ Organization seeks to improve the competitive advantages through comparison better internally and externally, including can improve the current performance and to upgrade the level of quality and further cost reduction.
6. The situation (c) the organization would begin in the application of methods to reduce the cost to start its efforts from the application of the "architecture value", both with regard to the analysis of the operations or product analysis as follows:

For the analysis of the process: the organization was trying to identify the host activities and activities of host-value, seeks the first development through the support of important factors affecting those activities, minimization or the second excluded taking into account the negative impact on the overall performance of the level of quality target. In addition to the organization sought to arrange activities of each operation with a view to reducing the time of achievement. Here the organization can use many of the methods developed such as production in the appropriate time JIT, scheduling of resources, and the reorganization of production lines in the light of the foundations of the manufacturing systems floppy.

For the analysis of the product: Start the organization clearly the functions of the current product, and to assess the extent of compliance with the wishes of the clients, and generate the competitive advantages of the Organization in the product market. The following inventory and identify the components of the product, and the function of each component in preparation for the design of the components with a view to the consolidation of some of the components together within the framework of the development of posts, or change the materials used, and the development of a method of production, including lead to reduce the cost and time of production and does not affect the level of quality in decline. In the light of the foregoing, the product design and taking into account the development of functional performance including contribute in support of the competitive advantages of the debtor.

7. The work of the Organization throughout the continuous improvements on performance, including supports their competitiveness through better comparative benchmarking internally and externally.

8. The organization seeks to improve the value of all parties associated with the Organization and those affected by their activity through the effective application of the foundations of the management of the value chain, which depend to a large extent on information generated from the analysis of the operations and analysis of the product, as well as the information generated by the application of binary cost in accordance with the activity and administration in accordance with the activity.

The second pillar: the development of new methods consistent with the trends of the expected change Conditions imposed economic reality that prevailed the world with the beginning of the twenty-first century, to economic units need to seek to expand its activities, and spread on the level of the world in the markets dominated by strong competition and increasingly, which requests the need to develop an integrated strategy to coordinate economic units of interrelated activities within the framework of the concepts of the foundations of the value chain; which aim to reduce both the costs and risks, latency of achievement in each workshop series - one of the interrelated activities - from the production and delivery of the requirements of the activity through the activities of the 


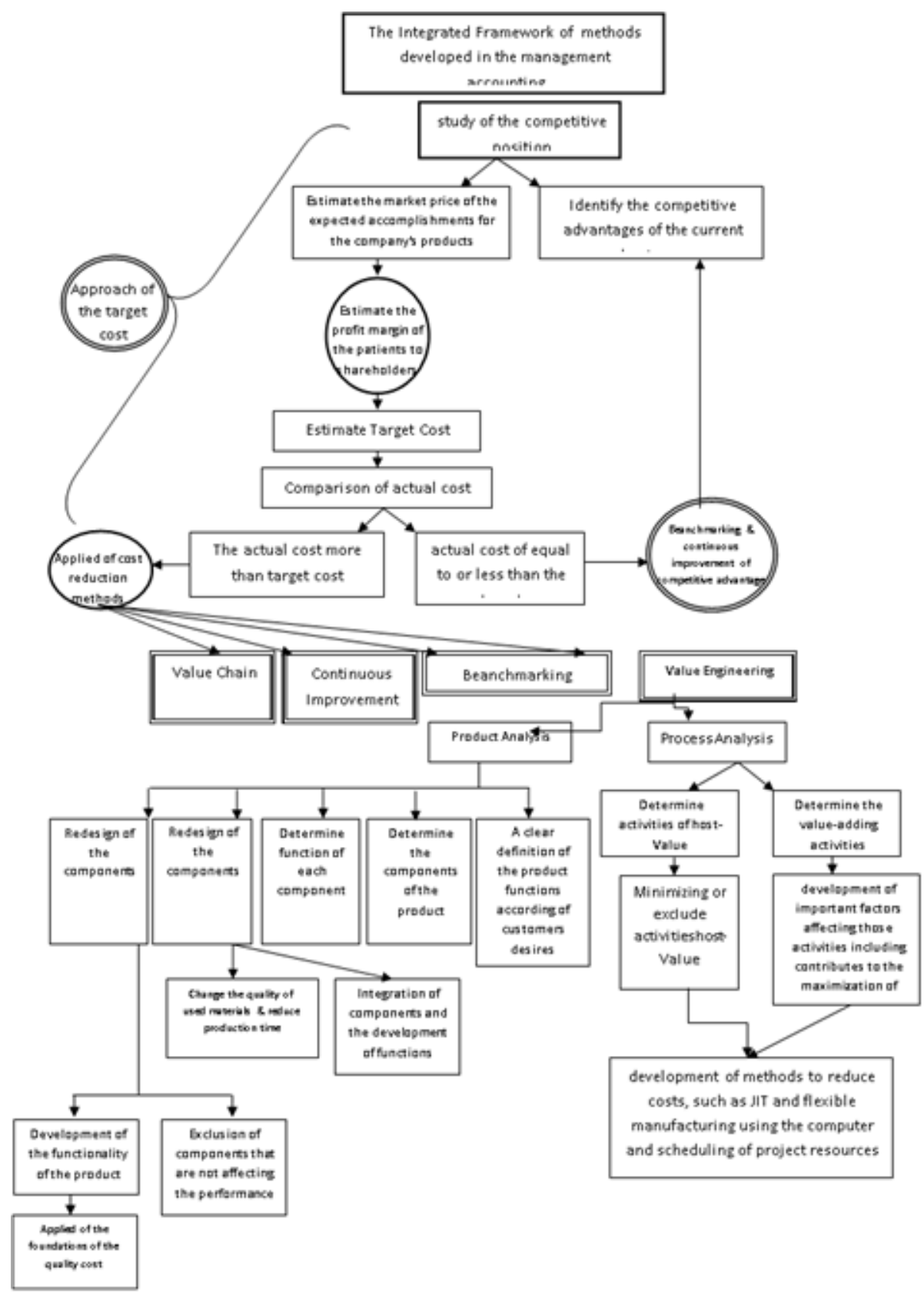

Fig 1

production and marketing of supporting activities (logistics) and ending with the arrival of the Product (a commodity or service) consumer, including contribute to maximize the values achieved for all the activities of the series. The idea of the value chain of an overview of the major industrial companies to their vendors, within the framework of the applied system of production at the appropriate time JIT systems and flexible manufacturing using a computer, where it no longer consider them from the standpoint of their commodity supplies or services only, but focused its attention on the extent of their ability to continue to supply, and negotiating the standards and inspires their systems of contribute in support of the efforts of those companies to maintain their competitiveness and improvement.

Numerous forms of response for the implementation of the value chain, while some economic units of the Eu series integration within the framework of one of the legal forms, another form called "Network Group", a number of integrated companies in terms of production and distribution, which seeks to link them through a network of contacts to exchange of important information to help them to improve their operations and to upgrade the level of quality and cost reduction, including leading in the end to improve the Operations Group and activities carried out in the various constituent units of the group, which was reflected in the improvement of the value chain in the competitive advantages of the group in the world markets. That was clear in the strategy followed by many Japanese companies founded on the exchange of information as a key element to link between the activities of companies of the value chain as a means to rationalize the decisions to improve the added value of all parties associated with the daisy chain. Where each unit, regardless of the nature of the activity or legal form to develop and test ways and methods which could reduce the cost and time of achievement, risk management and to contribute to the maximization of the value of each workshop 
and the value chain, and contributes to the achievement of competitive advantages of each of the participating units in the series.

Can be limited differences between units of traditional economic and the other components of the Network Group of many aspects of [27] [28] [29]:

\section{1) Strategies:}

Of conventional units operating the centrality of the length of the life cycle of the product, and marketing strategy limited, focusing on local markets or regional organizations within the framework of the objectives of the limited competitive. Often take organizational structure figure horizon. Either in The Network Group are relying on world markets, and the application of the methods of electronic trade both for resources or marketing of production, within the framework of the objectives of multiple competitive and the life-cycle of a product short-term.

\section{2) The operational decisions:}

The economic units traditional macroeconomic planning and production in the light of the precise forecasting and consistency of each of the production cycle procurement decisions and industrialization in the short term. While the group companies the retina access to goods and services through the planning of the project resources Enterprise Resource Planning (ERP) and partnership between suppliers and producers and marketers, with a focus on management, production and exchange of information between the units of the Group [30].

3) The operational control:

Apply economic unit's traditional production systems, production, storage and systems of quality control. While applied group, companies manufacturing systems, flexible, scheduling orders among units of the group.

\section{4) Procurement Support activities:}

Usually adopt economic units in the traditional national markets in procurement, characterized by a decline in the level of competition, lack of attention to supporting activities (logistics); with a focus on the costs and not customer service; while in the Network Group operations are considered the contractual procurement based on negotiation and the speed and flexibility, and depends on the electronic markets in many cases, with interest the activities help to develop relations with suppliers, focus on customer service.

\section{5) Management of knowledge:}

Of the economic units and traditional lack of interest in investment in knowledge capital, with reliance on knowledge workers, the lack of information technology skills, which consequently lead to a lack of creativity and innovation. While expanding the network group in investment in knowledge capital, education and appropriate training for the continuous workers, to encourage creativity and innovation.

\section{6) Information technology:}

Adopt economic units in the traditional methods of computeraided design $\mathrm{CAD}$, industrialization and with the help of the computer CAM with interest the functional complementarity, investment in information technology. As the Network Group on the integration of the supply chain, external integration of the Organization and to invest domestically and externally in information technology.
The emergence of the web companies[31] to the development of the relations between the companies of the network, which represent the basis of the terms of a series of value, was dealing on a competitive basis, and moved to the stage of interdependence and cooperation to improve overall performance from the perspective of the goal of maximizing the value of the total of its activities to all parties associated with a series of value from the producers and suppliers of commodity supplies and service to clients, to ensure the achievement of a rewarding return to shareholders and the owners, with ensuring the survival and the continuity and growth of the group companies through continuous improvements in competitiveness. One of the most important changes resulting from the emergence of web companies as a result of changes in the economic environment:

1. The growing importance of the availability of confidence in the mutual information and the joint efforts of the basis to support and develop relations the indissoluble link between the units of the Network Group.

2. The growing importance of information technology management and knowledge and the development of trust and confidence between the terms of the network, which resulted in the emergence of a new costs, requires the need to develop benchmarks and processors special accounting, appropriate methods to assess performance.

3. The increasing importance of inventory management, which represents a major challenge in the system of the Network Group.

4. The change in the composition of the importance of cost elements due to bring engineers, programmers replace a force work in factories, increasing direct and indirect costs associated with the design of the product engineering, marketing and distribution to limit which increased the increase of the proportion of direct costs.

5. The fundamental changes in the organization and information technology used in conjunction with the events of the corresponding changes in cost systems and the measurement of performance evaluation, where the systems of traditional costs and the improvements as a result of the application of some of the entrances and developed as an input to the cost in accordance with the activity, the target cost is no longer sufficient to support the competitiveness in the marketing environment and rapidly changing.

The basic requirements for the effective management of the value chain in the Network Group are as follows:

1. The establishment of a data is collected and processed in accordance with logical standards acceptable to the various constituent parties of the series is to provide information that would contribute to the composition of the vision and the future of the objectives of the group, and contribute to the elaboration of effective mechanisms to achieve them.

2. Improving the communications infrastructure between companies of the network, to contribute to the improvement of the process of the internal exchange of data and information electronically through the achievement of high speed in contact and reliability and acceptance by the parties of the network.

3. The development of systems to measure the costs compatible with the nature of the needs of the activities of the value chain in the Network Group. 
4. The development of methods to measure and assess performance from a strategic perspective, take in the broad sense of performance and financial aspects and social, emergent need urgent developments imposed by the successive rapid in world markets, and the consequent change in the forms of the reluctance of economic units, which aims to address the prevailing competition, through the achievement of more competitive advantages that enables it to control the markets.

Because the performance measurement and evaluation is the focal point for the success of any economic unit aims at achieving profit, since it provides information to achieve a deeper understanding of the various aspects of the activity and the factors affecting, helping to form an organizational behavior contribute to improving the competitiveness of the Unit; it has sought to many researchers[32][33][34] to exert more effort for the development of models of measurement and assessment of performance, and mechanisms to ensure that the Organization is implemented efficiently and effectively. The motivation to many reasons, including:

1. Arising from the relations of the new connectivity between the companies of the value chain from the effects require changes in existing systems in these companies, commensurate with the objectives to be achieved through the cooperation among them.

2. The systems of the current costs and provide information for measuring the cost of various activities, but it does not provide the necessary information to evaluate the efficiency of the implementation of the actions contained in those activities.

3. The dependence on career tab under the current costs and the improves performance at the macro level of the Organization, but it does not fit under the overlap of the functional areas arising from the use of information technology, the new format of the relations between the economic units participating in the Network Group composed of a series of value.

4. The inadequacy of the current processor for overhead costs under the management of the value chain within the network group of relations and objectives required achieved.

5. The current systems do not encourage and stimulate the development, and do not provide adequate information necessary to improve the quality of the administrative decision.

\section{CONCLUSION}

It must be based on new systems to measure the costs and performance assessment to identify the important factors affecting the success of every activity of economic unity, then develop standards of accounting models can be relied on to improve the measurement and assessment of the performance of those activities, including the provision of information to assist the Department of each unit within the network in the operations of the planning and control with a view to improving the operational performance of the organizational and then competitiveness, taking into account:

1. The focus on improving performance in the activities associated with creating value in each unit within the group, in the light of the complementary relations between constituent units of the network.
2. The focus on knowledge management through a system of the costs associated with the performance, where good information to provide deep understanding contribute to focus efforts to improve overall performance.

\section{REFERENCES}

[1] Arena, Marika; Conte, Antonio \& Marco Melacini: "Linking is displayed environmental accounting to reward systems: the case of the Environmental besides and loss account", Journal of Cleaner Production 108 (2015) 625-636.

[2] mm Allen wrench, Brennan G.: "What's new about New accounts? Assessing the change proposals for social and environmental accounting, Accounting Forum 38 (2014) 278-287.

[3] Maa, Tiejun, Tang Leilei b, Frank McGroartya, MingChien Sunga \& Johnnie E. V Johnsona: "Time is money: Costing the impact of duration misperception in market prices," European Journal of Operational Research 255 (2016) 397-410.

[4] Galles is just, Waldo will be shown, Mieke Vandenbroucke \& Niels De Temmerman: "Life cycle costing as an early stage feasibility analysis: The adaptable transformation of Willy Van Der Meeren's student residences," Procedia Economics and Finance 21 ( 2015 ) 14 - 22.

[5] Klovienè, Lina \& Edita Gimzauskiene:" The Effect of Information Technology on Accounting System's conformity with Business Environment: A Case Study In Banking Sector Company", Procedia Economics and Finance 32 ( 2015) 1707 - 1712.

[6] Papazov, Emil \& Lyudmila Mihaylova: "Organization of Management Accounting Information in the context of Corporate Strategy", Procedia - Social and Behavioral Sciences, and 213 (2015) 309 - 313

[7] Trigo, António, Fernando Belfo \& Raquel Pérez Estebanez: "Accounting Information Systems: The Challenge of the Real-Time Reporting", Procedia Technology 16 (2014) 118 - 127.

[8] Porter, L.J. \& Rayner, P. Op. 15, pp. 69-81.

[9] Robert Kee, Michele Matherly, Op. 15 , pp. 267-292.

[10] Unglert, Johannes; Sipke Hoekstra; Juan Jauregui-Becker \& Fred van Houten: 1970-1990 "décision - support for reconfigurable manufacturing systems based on 10 Synthesis ,", Procedia CIRP 41, 2016, 153 - 158.

[11] Jiang, Zheng \& Huimin v.: "The selection of firms based on productivity: different roles of entry and overhead cost", Economic Modelling 54, 2016, 537-544.

[12] Tenhiälä, Antti \& Pekka Helkiö: "Performance effects of the bidirectional adjustment an ERP system for manufacturing planning and control under dynamic market requirements", Journal of Operations Management 36 (2015) 147-164. The

[13] Mohammadi, Babak; Ata Allah Taleizadeh; Rasoul Noorossanaa \& Hadi Samimi: "Optimizing integrated manufacturing and products inspection policy for deteriorating manufacturing system with imperfect inspection", Journal of Manufacturing Systems 37 (2015) 299-315. 
[14] Sriram, R.S.: "Accounting Information System issues of FMS", Integrated Manufacturing System, Vol. 6, No. 1, 1995, PP. 47-63.

[15] D'Iribarne, E. \& Study, B.: "Work Organization in Flexible Manufacturing System: First finding from international comparisons" In Martin, T., (ed.), the Design of Work in Automated Manufacturing System", Pergamen Press, Oxford, 1984, pp. 127-132.

[16] Gosselin, M.: "The effect of strategy and of the structure on the adoption and implementation of the activity-based costing", Accounting Organization and society, 1997, pp. 105-122.

[17] Macintosh, N. B.: "Management Accounting and Control Systems", Chichester, U.K.: John Wiley \& Sons, 1994, pp. 122, 124.

[18] Alleanza Nazionale, G. \& Salvador, F.: Information Flows for High-performance k.s.c." International Journal of Production Economics, Vol. 70, 2001, pp. 21.36.

[19] Hunton, J. \& Flowers, L.: "Information Technology in the Accounting Method: Assessing the impact on accounts and organizations", Advances in Accounting Information Systems 5, 1999.

[20] David, J.S., Dunn, C. L. Oxon \& McCarthy, W.E.: "The Research Pyramid: A Framework for Accounting Information System Research", Journal of Information Systems, Vol. 13, No. 1, Spring 1999, pp. 7.30.

[21] Cooper, R. \& Slagmulder, R.: "Target Costing and Value Engineering" Productivity Press, NJ: The IMA Foundation for Applied Research, Inc., 1997, 139

[22] Lockamy, E. \& Cox, J. F. Op. 15, pp. 1661-1672.

[23] Sethi, V. \& Duffy, K.,: "Reengineering for Business Processes," Encyclopedia of Information Systems, 2004, pp. 647-659.

[24] Attaran, M.,: "the newsletter was between information technology and business process reengineering", Information \& Management, Volume 41, Issue 5, May 2004, pp. 585-596.

[25] Kaszubski, Michael E. \& Steve Ebben: Bidirectional Adjustment "activity-based costing to implement behavioural cost initiatives with a message confirming",
Journal of Facilities Management VOL control knob. 3 No. 2, 2010, pp. 184 - 192.

[26] Saunders, Max; Robin Mann \& Robin Smith: "Benchmarking strategy deployment as well as", Benchmarking: An International Journal, vol. 14, No. 5, 2007, pp. 609-623

[27] Tomkins, C., "Interdependencies, trust and information in relationships, alliances and networks", Accounting, organizations and Society, 26, 2001, pp. 161-191.

[28] D'Amours, S., Montreuil, B., Lefrancois, P., Soumis, F.,: "Networked k.s.c.: The impact of information sharing", International Journal of Production Economics 58, 1999, pp. 63-79.

[29] Briers, M., Chua, W.F.,: "The role of actor-networks and boundary objects in management accounting change: a field study of an implementation of the activity-based costing", Accounting, Organization and Society, 26, 2001, pp. 237-269.

[30] Jackson, Leonard E.: "enterprise resource planning systems: revolutionizing lodging human resources. The management", Worldwide Hospitality and Tourism Themes Vol. 2, No. 1, 2010, pp. 20-29.

[31] Examples of such companies in Egypt telecoms, iron and steel and pharmaceutical companies, which have become working within the network environmental seeking to maximize value

[32] Brouthers, L.E., Mukhopadhyay, T. J., Wilkinson, T.J. \& Brouthers, K.D.: "International market selection and subsidiary performance: A neural network approach", Journal of World Business, Vol. 44, No. 3 , 2009, pp. 262-273

[33] Verbeeten, F. \& Boons, E.,: "strategic priorities, performance measures and performance: an empirical analysis in Dutch firms," European Management Journal, 26, September 2009, 113-128.

[34] Masquefa, B.,: "Top management adoption of a locally driven performance measurement and evaluation system: a social network perspective", Management Accounting Research, Volume 19, Issue 2, June 2008, pp. 182-207. 